\section{BMJ Paediatrics Open}

\title{
Parents' perceptions of core outcomes in neonatal research in two Nigerian neonatal units
}

Sarah Kathryn Read (D) , ${ }^{1}$ Aisha Jibril, ${ }^{2}$ Olukemi Tongo, ${ }^{3}$ Abimbole Akindolire, ${ }^{3}$ Isa Abdulkadir, ${ }^{2}$ Helen Nabwera, ${ }^{4}$ Ian Sinha, ${ }^{5}$ Stephen Allen, ${ }^{1,6}$ The Neonatal Nutrition Network

To cite: Read SK, Jibril A, Tongo 0, et al. Parents' perceptions of core outcomes in neonatal research in two Nigerian neonatal units. BMJ Paediatrics Open 2020;4:e000669. doi:10.1136/ bmjpo-2020-000669

- Additional material is published online only. To view please visit the journal online (http://dx.doi.org/10.1136/ bmjpo-2020-000669).

SKR and AJ are joint first authors.

IS and SA are joint senior authors.

Received 22 February 2020 Revised 20 April 2020 Accepted 6 May 2020
Check for updates

\section{(C) Author(s) (or their} employer(s)) 2020. Re-use permitted under CC BY. Published by BMJ.

For numbered affiliations see end of article.

Correspondence to Sarah Kathryn Read; sarah. read@talktalk.net

\begin{abstract}
Background There is a scarcity of information regarding the most important outcomes for research in neonatal units in low-resource settings. Identification of important outcomes by different stakeholder groups would inform the development of a core outcome set (COS) for use in neonatal research.
\end{abstract}

Objective To determine the perceptions and opinions of parents of newborn babies regarding what outcomes were most important to them in order to contribute towards development of a COS for neonatal research in subSaharan Africa.

Methods Semistructured interviews were undertaken with parents, mostly mothers, of babies admitted to one neonatal unit in North central and one in Southwest Nigeria. Participants were purposively sampled to include parents of babies with common neonatal problems such as prematurity.

Results We conducted 31 interviews. The most frequently raised outcomes were breast feeding, good health outcomes for their baby, education, growth and financial cost. Parents placed more emphasis on quality of life and functional status than health complications.

Conclusions The opinions of parents need to be considered in developing a COS for neonatal research in low-resource settings. Further research should assess the opinions of families in other low-resource settings and also engage a broader range of stakeholders.

\section{INTRODUCTION}

Although under-5 survival has improved worldwide, a child's greatest risk of dying remains in the first 28 days of life: $47 \%$ of all under-5 deaths occur in the neonatal period. ${ }^{1}$ Effective perinatal care can have a dramatic impact on reducing the number of neonatal deaths, but little high-quality neonatal research to inform the development of interventions exists in low-resource settings.

Clinical trials are only as credible as their outcomes-the effects of an intervention. ${ }^{2}$ Key stakeholders, including parents and clinicians, are rarely involved in outcome selection; consequently, research may not be directly relevant to them. Relevance is necessary in

\section{What is known about the subject?}

Variation in outcome reporting in neonatal research has limited the ability of clinical trials and metaanalyses to identify the most effective treatments.

- Little is known of the priorities of key stakeholders for neonatal research in sub-Saharan Africa.

- Parents in sub-Saharan Africa have not been involved in the selection of clinical trial outcome measures.

\section{What this study adds?}

Outcomes prioritised by parents relate to family outcomes and quality of life, long-term consequences of disease and short-term disease activity.

- Parents should be engaged in identifying outcomes in future research to ensure relevance to al stakeholders.

order for outcomes to influence policy and practice. ${ }^{3-5}$ In addition, outcomes are often inconsistent, preventing the combining of results from different studies. A systematic review of studies reporting outcomes for babies in low-income and middle-income countries (LMICs) found great variation between outcomes measured and the definitions used; for example, only $60 \%$ of included studies measured survival as an outcome. ${ }^{26}$

Core outcomes sets (COSs) are groups of standardised outcomes that have been determined by key stakeholders as being the most important within a specific research field. Development and use of COS is important in developing high-quality research through standardised recording and reporting of research, reducing publication bias and facilitating systematic reviews. ${ }^{25}$ COSs have already been used successfully in some areas of medical research. An example is Outcome Measures in Rheumatology which involves multiple stakeholder groups to form outcome 
sets, leading to higher quality and more patient centred research. ${ }^{7}$ However, few studies critically assess the selection of appropriate outcomes for research specifically for children and neonatology in particular. Variation in outcomes measured in neonatal research has limited progress; much neonatal care is inadequately evidence based as high-quality evidence is lacking and neonatal trials and meta-analyses rarely result in conclusive recommendations. ${ }^{28}$

In order to formulate COS, research and systematic reviews need to be carried out to identify important outcomes to stakeholders. Existing research on perceptions of parents and family members relating to neonatal care is focused on high-income countries. These studies reveal that important considerations for these parents include stress, neurodevelopment, survival and breast feeding. ${ }^{9-11}$ However, research in neonatology is setting specific; research conducted in high-income countries may not be directly relevant to LMICs as the spectrum of disease differs, the same interventions are not available, cultural differences exist and adverse outcomes are much more common. ${ }^{2}{ }^{12}$ Consequently, research is needed in order to form the basis of a COS for neonatology in subSaharan Africa.

The Neonatal Nutrition Network (NeoNuNet; https:/ / www.lstmed.ac.uk/nnu) was established in 2018 to contribute to improving the evidence base for neonatal care in sub-Saharan Africa where the neonatal mortality rate is 27 per 1000 compared with a global rate of 18 per $1000 .{ }^{13}$ In Nigeria, only $39 \%$ of deliveries occur in health facilities and the neonatal mortality rate is 38 per 1000 live births. ${ }^{14}$ Acceleration of progress in addressing neonatal mortality in Nigeria is required to meet the global sustainable development goals target of 12 per 1000 or fewer deaths by 2030 to be met. ${ }^{1516}$

The aim of this study was to identify neonatal research outcomes that are most important to parents in Nigeria.

\section{METHODS}

This study engaged parents whose newborns were admitted to one of two tertiary neonatal units in contrasting regions of Nigeria allowing comparison of two different population groups. The neonatal unit at University College Hospital, Ibadan, is located in the Southwest with a mostly urban population. The main ethnic group is the Yoruba and the dominant religion is Christianity. ${ }^{17}{ }^{18}$ Neonatal mortality is 39 per 1000 live births and $1.7 \%$ of the population live in the lowest wealth quintile for Nigeria. ${ }^{19}$ In contrast, the neonatal unit at Ahmadu Bello University Teaching Hospita, Shika-Zaria, Kaduna, is located in North central Nigeria. The major ethnic groups are the Hausa and Fulani and the dominant religion is Islam. The population is mainly rural; $35.4 \%$ of the population live in the lowest wealth quintile and neonatal mortality rate is 44 per 1000 live births. ${ }^{19}$

We used semistructured interviews to achieve a balance between capturing information consistently, but also allowing families to raise issues of importance to them to avoid bias imposed by the research team. Interviews explored parents' experiences and perceptions of neonatal care ${ }^{520}$ regarding the time they spent in the neonatal units ${ }^{21}$ to formulate outcomes of importance to parents. Interviews were conducted on the neonatal units over a 4-week period in June 2019. No time limit was imposed on interviews to ensure all participants had the same opportunity to report their opinions. In line with similar previous research we aimed to conduct approximately 30 interviews across both units, ${ }^{5}$ but acknowledged that more may be required if saturation was not reached and new themes were still emerging from the data. ${ }^{22}$

Participants were purposively sampled to include parents of babies with prematurity/low birth weight, birth asphyxia and congenital malformations. Parents that were regularly present on the neonatal units were selected with the assistance of clinicians, and those who agreed to share their opinions were invited to participate. Parents were excluded if their baby was deemed particularly unwell or unlikely to survive to discharge, in order to prevent unnecessary distress. Parents whose babies had been admitted for less than 3 days were also excluded as they may not have had sufficient experience of neonatal care to be able to form opinions. Parents were interviewed individually or with their partner as they preferred in a private location on the neonatal unit. Information was given to potential participants and written consent obtained. It was made clear that declining to participate in the research would not affect the clinical care being given to their baby.

An interview guide (online supplementary 1) was developed by SKR to explore the opinions of parents. SKR led the research as part of an MSc and trained non-clinical student TA and resident doctor $\mathrm{AJ}$ in using the interview guide. Interviews were conducted in the parents' preferred language by SKR and TA in Ibadan and AJ in Zaria. All researchers were female. Time was taken to get to know the parents prior to interview.

The interview guide was piloted among three parents. Minor revisions were made, and these pilot data were included in the final analysis. Parents were asked to reflect on what they considered important when considering whether interventions for their baby were beneficial. All interviews were recorded, transcribed and anonymised before being translated into English by Tolulope Akinrinde and AJ. Transcriptions were supplemented by notes taken during the interviews. Transcripts and notes were not returned to participants.

All parents who were invited for interview agreed to participate in the study. Thirty-three parents ( 30 mothers and 3 fathers) were interviewed over 31 interviews; both parents participated in two of the interviews. Sixteen interviews were conducted in Ibadan and 15 in Zaria.

\section{Data analysis}

Analysis was iterative using an adapted framework analysis approach. ${ }^{22} 23$ The English transcripts were read 
Table 1 Characteristics of participants

\begin{tabular}{|c|c|c|c|}
\hline \multirow[b]{2}{*}{ Characteristic } & \multicolumn{2}{|c|}{ Location } & \multirow[b]{2}{*}{ Total } \\
\hline & Ibadan & Zaria & \\
\hline \multicolumn{4}{|l|}{ Relationship to baby N (\%) } \\
\hline Mothers & $15(45)$ & $15(45)$ & $30(91)$ \\
\hline Fathers & $3(9)$ & $0(0)$ & $3(9)$ \\
\hline Total & $18(55)$ & $15(45)$ & $33(100)$ \\
\hline \multicolumn{4}{|l|}{ Sex of baby $N(\%)$} \\
\hline Male & $6(19)$ & $11(34)$ & $17(53)$ \\
\hline Female & $11(34)$ & $4(13)$ & $15(47)$ \\
\hline Total & $17(53)$ & $15(47)$ & $32(100)^{\star}$ \\
\hline \multicolumn{4}{|l|}{ Maternal education status $\mathrm{N}(\%)$} \\
\hline University graduate or equivalent & $7(23)$ & $6(19)$ & $13(42)$ \\
\hline $\begin{array}{l}\text { Senior secondary school certificate holders who have teaching or other } \\
\text { professional training }\end{array}$ & $3(10)$ & $1(3)$ & $4(13)$ \\
\hline $\begin{array}{l}\text { Senior secondary school certificate holders or grade II teachers } \\
\text { certificate holders equivalent }\end{array}$ & $4(13)$ & $2(6)$ & $6(19)$ \\
\hline JSS3† or primary six certificate & $2(6)$ & $5(16)$ & $7(23)$ \\
\hline Those who can either just read or write or are illiterate & $0(0)$ & $1(3)$ & $1(3)$ \\
\hline Total & $16(52)$ & $15(48)$ & $31(100)$ \\
\hline \multicolumn{4}{|l|}{ Maternal occupation N (\%) } \\
\hline $\begin{array}{l}\text { Senior public servants, professionals, managers, large scale traders, } \\
\text { businessmen and contractors }\end{array}$ & $1(3)$ & $0(0)$ & $1(3)$ \\
\hline Intermediate grade public servants and senior school teachers & $2(6)$ & $1(3)$ & $3(10)$ \\
\hline Junior school teachers, drivers and artisans & $6(19)$ & $2(6)$ & $8(26)$ \\
\hline Petty traders, labourers, messengers and similar grades & $4(13)$ & $0(0)$ & $4(13)$ \\
\hline Unemployed, students, full-time housewives and subsistence farmers & $3(10)$ & $12(39)$ & $15(48)$ \\
\hline Total & $16(52)$ & $15(48)$ & $31(100)$ \\
\hline
\end{tabular}

*One mother had twins on the neonatal unit.

†Junior secondary school examination.

multiple times by SKR and recurring themes noted. These themes were then coded before related codes were grouped together to form broad themes. As each new transcript was read, it was compared with those coded previously to ensure consistency. Rather than using a coding framework, broad themes were rephrased as outcomes and discussed at a NeoNuNet meeting comprising of neonatal clinical leads and the research team. To prioritise outcomes, those mentioned only once were discarded and those remaining were listed in order of how commonly they were discussed by the participants.

The Consolidated criteria for Reporting Qualitative research reporting guidelines were used. ${ }^{24}$

\section{RESULTS}

Participant characteristics are shown in table 1. Mean maternal age was 29 years (range 18-44 years). Across both neonatal units, 13 out of 31 mothers had been to university; 7 in Ibadan and 6 in Zaria. However, 15 were either unemployed or full-time housewives but there was significant variation between the two units- 3 in Ibadan but 12 in Zaria. Most participants in Ibadan were Christian and all participants in Zaria were Muslim. Two parents had previously had babies who were admitted to the same neonatal unit.

Median gestation at delivery was 35 weeks (range 26-40 weeks) and median birth weight was $1.75 \mathrm{~kg}$ (range $0.75-3.90 \mathrm{~kg}$ ). The mean duration of admission prior to interview was 6 days (range 3-17 days). These factors were similar in both neonatal units (data not shown). The main reason for admission of the babies are shown in table 2. Prematurity/low birth weight was the primary indication for admission in a greater proportion of babies in Ibadan than Zaria.

Interviews lasted between 10 and $30 \mathrm{~min}$. Parents identified 22 broad outcomes. Three were only mentioned in one interview and so were excluded (passing of stool, appropriate sleeping, normal temperature). The most commonly identified outcomes are presented with illustrative quotes in table 3: breast feeding, good 
Table 2 Main clinical indication for admission of the babies

\begin{tabular}{|c|c|c|c|c|c|}
\hline Location & $\begin{array}{l}\text { Very premature (gestation }<32 \text { weeks) or } \\
\text { very low birth weight }(<1500 \mathrm{~g}) \\
\mathrm{N}(\%)\end{array}$ & $\begin{array}{l}\text { Asphyxia } \\
\text { N (\%) }\end{array}$ & $\begin{array}{l}\text { Congenital malformation* } \\
\mathrm{N}(\%)\end{array}$ & $\begin{array}{l}\text { Othert } \\
\text { N (\%) }\end{array}$ & $\begin{array}{l}\text { Total N } \\
(\%)\end{array}$ \\
\hline Ibadan & $10(31)$ & $1(3)$ & 1 (3) & $5(16)$ & $17(53)$ \\
\hline Zaria & $2(6)$ & $4(13)$ & $2(6)$ & 7 (22) & $15(47)$ \\
\hline Total & $12(38)$ & $5(16)$ & $3(9)$ & $12(38)$ & $32(100)$ \\
\hline
\end{tabular}

*Posterior urethral valves, cystic hygroma, spina bifida.

†Gestational age 32-36 weeks, low birth weight $<2500 \mathrm{~g}$, jaundice, sepsis.

health outcomes for baby, education, growth, religious factors and financial cost. Table 4 shows the full list of outcomes identified by parents, ranked by how often they were mentioned. When grouped into broad outcome domains, it was clear parents were concerned with family outcomes and quality of life, long-term consequences of disease and short-term illnesses.

Across both units, the main concerns of parents related to breast feeding and good health outcomes for the baby. More parents in Ibadan mentioned concerns regarding educational ability, growth and length of hospital stay than parents in Zaria. Both groups of parents frequently mentioned the importance of religion with regard to outcomes for their baby and their faith they have in God.

No new themes were identified by parents in the final six interviews; therefore, we considered that saturation had been achieved with the first 25 interviews.

\section{DISCUSSION}

This study provides insights into outcomes of neonatal care that are important to parents in two tertiary neonatal

Table 3 Illustrative quotes for the top six prioritised outcomes

\begin{tabular}{ll}
\hline Outcome & Illustrative quotes \\
\hline Breast feeding & 'I feel that because they're [healthcare workers] not allowing me to breastfeed I feel that baby is not \\
well yet' (mother, Ibadan). \\
'If the baby can breastfeed directly by herself then it shows that she has improved more than she \\
was' (mother, Ibadan). \\
'What will fill my joy is(...)breastfeeding the baby, instead of looking at him from afar' (mother, \\
Ibadan) \\
'I want the baby to take more of the breast milk(...)I want her to be able to feed' (mother, Zaria). \\
Good health outcomes \\
for baby
\end{tabular}


Table 4 Outcomes identified during interviews with parents according to site and ranked by overall frequency

\begin{tabular}{|c|c|c|c|c|}
\hline Rank & Outcome domain & $\begin{array}{l}\text { Total no of times identified } \\
\mathrm{N}(\%)\end{array}$ & $\begin{array}{l}\text { Times identified in Ibadan } \\
\mathbf{N}(\%)\end{array}$ & $\begin{array}{l}\text { Times identified in Zaria } \\
\text { N (\%) }\end{array}$ \\
\hline 1 & Breast feeding & $22 / 31(71)$ & $11 / 16(69)$ & $11 / 15(73)$ \\
\hline 3 & Education & $16 / 31(52)$ & $10 / 16(63)$ & $6 / 15(40)$ \\
\hline 4 & Growth & $16 / 31(52)$ & $11 / 16(69)$ & $5 / 15(33)$ \\
\hline 6 & Financial cost & 11/31 (35) & 7/16 (44) & $4 / 15(27)$ \\
\hline 7 & Length of hospital stay & 9/31 (29) & $8 / 16(50)$ & $1 / 15(7)$ \\
\hline 8 & Survival to discharge & $8 / 31(26)$ & $5 / 16(31)$ & $3 / 15(20)$ \\
\hline 9 & $\begin{array}{l}\text { Jobs or future } \\
\text { achievements }\end{array}$ & $7 / 31(23)$ & 6/16 (38) & $1 / 15(7)$ \\
\hline 12 & Breathing & $5 / 31(16)$ & 2/16 (13) & $3 / 15(20)$ \\
\hline 13 & Baby able to cry & $5 / 31(16)$ & $0(0)$ & $5 / 15(33)$ \\
\hline 14 & Jaundice & $5 / 31(16)$ & $1 / 16(6)$ & $4 / 15(27)$ \\
\hline 15 & Phototherapy & $4 / 31(13)$ & $4 / 16(25)$ & $0(0)$ \\
\hline 16 & Able to hold baby & $3 / 31(10)$ & 3/16 (19) & $0(0)$ \\
\hline 17 & Medications & $3 / 31(10)$ & 2/16 (13) & $1 / 15(7)$ \\
\hline 18 & Development & $2 / 31(6)$ & $1 / 16(6)$ & $1 / 15(7)$ \\
\hline 19 & Survival to adulthood & $2 / 31(6)$ & $2 / 16(13)$ & $0(0)$ \\
\hline
\end{tabular}

${ }^{*}$ Refers to the influence of religion on outcomes for babies, beliefs of the parents that outcomes are in the hands of God.

units in Nigeria. These findings can be used to inform the development of COS for neonatal research in subSaharan Africa.

It is clear that parents were concerned with issues they were facing as part of their lived experience of having a baby on the neonatal unit. The most frequent outcome identified by parents was breast feeding; the ability to breastfeed was felt by most to be a sign of improvement in their baby. Growth was also raised as a key concern. The link between good feeding and growth was raised by parents and is well known. ${ }^{25}$ Parents also identified long-term outcomes as important; they specified that education of their child in particular was important to them, as were future jobs and achievements. However, this is rarely identified as a concern in existing research. ${ }^{5}$ Although challenging, greater emphasis on long-term follow-up would enhance the relevance of future research to parents. The financial cost to the family of the current admission was also frequently mentioned by parents but again, do not appear in research from high-income countries. This is not surprising as the relative expenses associated with healthcare are much greater in Nigeria than they are in high-income settings, highlighting the importance of context-specific outcome sets. ${ }^{2627}$

Mortality is a key measure of neonatal outcome ${ }^{6}$ and so it was surprising that mortality was rarely mentioned in interviews. This may suggest a fatalistic attitude towards the death of a newborn due to the high rates of neonatal mortality, as most parents interviewed had low birth weight infants whose risk of mortality would be high. However, it is important to put this in the perspective that babies who were severely unwell or not likely to survive were excluded from this study. Religious beliefs were mentioned in about half of interviews, suggesting that they may be valuable coping strategies in an environment where adverse outcomes for newborns are common. There is a lack of research on the impact of religious beliefs on neonatal care although their impact on uptake of maternal health services has been studied. ${ }^{28}$ Religious beliefs were mentioned frequently across both locations in our study, highlighting that religious beliefs may affect attitudes towards neonatal care in both Christian and Muslim populations of Nigeria. Further research would help delineate how these values shape attitudes and priorities of parents, and also healthcare workers, in relation to newborn care.

\section{Strengths and limitations}

Despite the overall similarity of results from each unit, researchers in other low-resource settings should interpret the transferability of our findings to their own contexts. We included two tertiary units located in major cities in two distinct regions of Nigeria; findings may not 
be transferable to other tertiary units or primary and secondary centres that care for neonates in these settings.

We excluded particularly sick babies and those thought unlikely to survive. Therefore, our findings are not directly relevant to this group. Most babies had been admitted for less than a week when their parents were interviewed. As such, parents may still be coming to terms with preterm delivery and/or having a sick baby and may not have had enough time to consider and formulate their longerterm concerns. Parents' opinions may change as hospital admission progresses. This should be considered in identifying important outcomes for interventions occurring towards the end of admission. Another limitation of our study was that few fathers were interviewed, limiting the results from these important stakeholders. Although we included parents of babies with common neonatal problems, their views may not be representative of parents whose babies have other conditions.

Parents may not have felt in a position to truthfully disclose concerns due to their vulnerable position as parents of sick babies receiving care on a neonatal unit, or their opinions may have been influenced by local health workers. Finally, all babies in this study required hospitalisation and so the results may not be generalisable to all newborn babies, even in settings with high neonatal mortality.

Lack of parental involvement in this study design is a major limitation to this study. However, our findings from this study can help guide patient and public involvement for further research in the development of COS.

In order to ensure that COS in neonatal research would be adopted by researchers, further research should engage a wider group of stakeholders including regulators, clinical trial authorities and policy-makers. We have identified outcomes of importance to parents; further research is required to standardise and validate the tools and measures used to evaluate these outcomes and the time points at which they are measured. This study highlights the need for development of COS in neonatology in order to improve outcomes for preterm infants and that future research in this field should consider the needs of families when prioritising research outcomes.

\section{CONCLUSIONS}

This study has identified outcomes of particular importance to parents of babies on tertiary neonatal units in two regions of Nigeria; breastfeeding, good health outcomes for baby, education, growth and financial cost. Our findings can inform further research in COS for neonatal trials in sub-Saharan Africa.

\footnotetext{
Author affiliations

${ }^{1}$ Department of Clinical Sciences, Liverpool School of Tropical Medicine, Liverpool, UK

${ }^{2}$ Department of Paediatrics, Faculty of Clinical Sciences, College of Medical Sciences, Ahmadu Bello University, Zaria, Kaduna, Nigeria

${ }^{3}$ Department of Paediatrics, College of Medicine, University of Ibadan, Ibadan, Oyo, Nigeria
}

${ }^{4}$ International Public Health, Liverpool School of Tropical Medicine, Liverpool, UK ${ }^{5}$ Respiratory Medicine, Alder Hey Children's NHS Foundation Trust, Liverpool, UK ${ }^{6}$ Department of Gastroenterology, Alder Hey Children's NHS Foundation Trust, Liverpool, UK

Acknowledgements We are grateful to the parents of babies admitted to the neonatal units in Ibadan and Zaria for contributing to our research. Thank you to Tolulope Akinrinde for her work as translator in Ibadan.

Collaborators Neonatal Nutrition Network members: Olusegun Akinyinka (College of Medicine, University of Ibadan, Nigeria); Dominic Umoru (Maitama District Hospital, Abuja, Nigeria); Chinyere Ezeaka (Lagos University Teaching Hospital, Nigeria); Ireti Fajolu (Lagos University Teaching Hospital, Nigeria); Beatrice Ezenwa (Lagos University Teaching Hospital, Nigeria); Zainab Imam (Massey St. Children's Hospital, Lagos, Nigeria); Martha Mwangome (KEMRI Wellcome Trust Research Programme, Kilifi, Kenya); Alison Talbert (KEMRI Wellcome Trust Research Programme, Kilifi, Kenya); Pauline Andang'o (Jaramogi Oginga Odinga Teaching and Referral Hospital, Kisumu, Kenya); Walter Otieno (Jaramogi Oginga Odinga Teaching and Referral Hospital, Kisumu, Kenya; Maseno University, Kisumu, Kenya); Grace Nalwa (Jaramogi Oginga Odinga Teaching and Referral Hospital, Kisumu, Kenya); Janneke van de Wijgert (University of Liverpool, Liverpool, UK); Melissa Gladstone (University of Liverpool, Liverpool, UK); Kevin Mortimer (Liverpool School of Tropical Medicine, Liverpool, UK); Graham Devereux (Liverpool School of Tropical Medicine, Liverpool, UK); Ismaela Abubakar (Liverpool School of Tropical Medicine, Liverpool, UK); Nicholas Embleton (Newcastle University, Newcastle, UK)

Contributors IS and SA conceived the project. SKR and AJ undertook the data collection in Nigeria. SKR performed the data analysis and wrote the first draft of the manuscript. All authors contributed to project design and data interpretation and approved the final manuscript.

Funding This project was completed as part of the Neonatal Nutrition Network, funded by a grant from the MRC Confidence in Global Nutrition and Health Research scheme (grant reference MC_PC_MR/R019789/1).

Competing interests None declared.

Patient and public involvement Patients and/or the public were not involved in the design, or conduct, or reporting, or dissemination plans of this research.

Patient consent for publication Not required.

Ethics approval Ethical approval was obtained from the Liverpool School of Tropical Medicine Research and Ethics Committee and the ethics committees at University College Hospital, Ibadan, and Ahmadu Bello University Teaching Hospital, Zaria.

Provenance and peer review Not commissioned; externally peer reviewed.

Data availability statement Data are available on reasonable request. Anonymised participant data along with original transcripts and coding is available from the research team on reasonable request.

Open access This is an open access article distributed in accordance with the Creative Commons Attribution 4.0 Unported (CC BY 4.0) license, which permits others to copy, redistribute, remix, transform and build upon this work for any purpose, provided the original work is properly cited, a link to the licence is given, and indication of whether changes were made. See: https://creativecommons.org/ licenses/by/4.0/.

ORCID iD

Sarah Kathryn Read http://orcid.org/0000-0003-2328-0992

\section{REFERENCES}

1 World Health Organization (WHO). Newborns: reducing mortality 2018. Available: https://www.who.int/news-room/fact-sheets/detail/ newborns-reducing-mortality

2 Webbe J, Brunton G, Afonso E, et al. The importance of core outcome sets and developing one for neonatal care. Infant 2017;13:70-2.

3 Sinha I, Jones L, Smyth RL, et al. A systematic review of studies that aim to determine which outcomes to measure in clinical trials in children. PLoS Med 2008;5:e96.

4 Williamson PR, Altman DG, Blazeby JM, et al. Developing core outcome sets for clinical trials: issues to consider. Trials 2012;13:132.

5 Webbe J, Brunton G, Ali S, et al. Parent, patient and clinician perceptions of outcomes during and following neonatal care: a 
systematic review of qualitative research. BMJ Paediatr Open 2018;2:e000343-e:e000343.

6 Gladstone M, Oliver C, Van den Broek N. Survival, morbidity, growth and developmental delay for babies born preterm in low and middle income countries - a systematic review of outcomes measured. PLoS One 2015;10:e0120566.

7 Tugwell P, Boers M, Brooks P, et al. OMERACT: an international initiative to improve outcome measurement in rheumatology. Trials 2007;8:38

8 Sinclair JC, Haughton DE, Bracken MB, et al. Cochrane neonatal systematic reviews: a survey of the evidence for neonatal therapies. Clin Perinatol 2003;30:285-304.

9 Brødsgaard A, Zimmermann R, Petersen M. A preterm lifeline: early discharge programme based on family-centred care. J Spec Pediatr Nurs 2015;20:232-43.

10 Jaworski M, Janvier A, Lefebvre F, et al. Parental perspectives regarding outcomes of very preterm infants: toward a balanced approach. J Pediatr 2018;200:58-63.

11 Sisk P, Quandt S, Parson N, et al. Breast milk expression and maintenance in mothers of very low birth weight infants: supports and barriers. J Hum Lact 2010;26:368-75.

12 Webbe J, Brunton G, Ali S, et al. Developing, implementing and disseminating a core outcome set for neonatal medicine. BMJ Paediatr Open 2017;1:e000048-e:e000048.

13 World Bank Group. World development indicators, 2019.

14 National Population Commission (NPC) [Nigeria], ICF. Nigeria demographic and health survey 2018 key indicators report. Abuja, Nigeria and Rockville, Maryland, USA: NPC and ICF, 2019.

15 Morakinyo OM, Fagbamigbe AF, Neonatal FAF. Neonatal, infant and under-five mortalities in Nigeria: an examination of trends and drivers (2003-2013). PLoS One 2017;12:e0182990.

16 Network TSDGCfAaSDS. Africa SDG index and Dashboards report 2018. Kigali and New York, 2018.

17 Adetola AO, Tongo OO, Orimadegun AE, et al. Neonatal mortality in an urban population in Ibadan, Nigeria. Pediatr Neonatol 2011;52:243-50.
18 Adelekan IO. Urban Africa risk knowledge: Ibadan City diagnostic report. Ibadan University, UK department for international aid and development, economic and social Research Council, 2016.

19 National Population Commission (NPC) [Nigeria], ICF International. Nigeria demographic and health survey, 2013. Abuja, Nigeria Maryland, USA, 2014

20 Britten N. Qualitative research: qualitative interviews in medical research. British Medical Journal (BMJ), 1995.

21 Pope C, Mays N. Reaching the parts other methods cannot reach: an introduction to qualitative methods in health and health services research. BMJ 1995;311:42-5.

22 Chandler CIR, Reynolds J, Palmer JJ, et al. Act Consortium guidance: qualitative methods for international health intervention research, 2013.

23 Clark KR, Vealé BL. Strategies to enhance data collection and analysis in qualitative research. Radiol Technol 2018;89:482CT-5.

24 Tong A, Sainsbury P, Craig J. Consolidated criteria for reporting qualitative research (COREQ): a 32-item checklist for interviews and focus groups. Int J Qual Health Care 2007:19:349-57.

25 Horta B, Victora C. Long-Term effects of breastfeeding: a systematic review. WHO, 2013.

26 Rutherford M, Mulholland K, Hill P. How access to health care relates to under-five mortality in sub-Saharan Africa: systematic review - Rutherford - 2010 - Tropical Medicine \& International Health - Wiley Online Library. Tropical Medicine and International Health, 2010.

27 Adedini SA, Odimegwu C, Bamiwuye O, et al. Barriers to accessing health care in Nigeria: implications for child survival. Glob Health Action 2014;7:23499.

28 Adewuyi EO, Auta A, Khanal V, et al. Prevalence and factors associated with underutilization of antenatal care services in Nigeria: a comparative study of rural and urban residences based on the 2013 Nigeria demographic and health survey. PLoS One 2018;13:e0197324. 